\title{
SUKU FABACEAE DI KAMPUS UNIVERSITAS ISLAM NEGERI SYARIF HIDAYATULLAH, JAKARTA, BAGIAN 2: TUMBUHAN POLONG BERPERAWAKAN TERNA
}

\section{FABACEAE OF ISLAMIC STATE UNIVERSITY (UIN) SYARIF HIDAYATULLAH, JAKARTA, PART 2: LEGUME HERBS}

\author{
Priyanti $^{1^{*}}$, Arifin Surya Dwipa Irsyam ${ }^{2}$ \\ ${ }^{I}$ Prodi Biologi, Fakultas Sains dan Teknologi, UIN Syarif Hidayatullah Jakarta \\ ${ }^{2}$ Sekolah Pascasarjana, Program Biologi Tumbuhan, Fakultas Matematika dan Ilmu Pengetahuan Alam. Kampus IPB \\ Dramaga, Bogor
}

*Corresponding author: priyanti@uinjkt.ac.id

Naskah Diterima: 13 Februari 2017; Direvisi: 14 Maret 2017; Disetujui: 23 Maret 2017

\begin{abstract}
Abstrak
Suku Fabaceae adalah tetumbuhan yang memiliki buah bertipe polong. Suku tersebut selain berperawakan pohon juga berupa terna. Anggota suku Fabaceae (polong) banyak ditemukan di sekitar lingkungan manusia termasuk di Kampus Universitas Islam Negeri (UIN) Syarif Hidayatullah, Jakarta. Informasi mengenai keanekaragaman tumbuhan polong yang berupa terna di Kampus UIN Syarif Hidayatullah belum tersedia. Penelitian dilakukan menggunakan metode jelajah di kampus I dan II serta studi pustaka. Sebanyak 3 jenis tumbuhan polong berperawakan terna telah didapatkan di lingkungan kampus, yaitu Arachis pintoi Krapov. \& W. C. Greg., Mimosa diplotricha C. Wright ex Sauvalle, dan M. pudica L. Jenis-jenis tersebut termasuk ke dalam 2 anak suku (Faboideae, Mimosoideae) dan 2 puak (Aeschynomeneae, Mimoseae). Jenis-jenis tersebut tumbuh di lokasi yang berbeda-beda. Tumbuhan polong yang hanya ditemukan di Fakultas Kedokteran dan Ilmu Keshatan (FKIK) adalah A. pintoi. Mimosa diplotricha ditemukan tumbuh di Pusat Laboratorium Terpadu Fakultas Sains dan Teknologi, Perpustakaan Utama, FKIK, Fakultas Sosial dan Ilmu Politik (FISIP), Wisma Syahida, Pusat Bahasa, dan Sekolah Pascasarjana, sedangkan $M$. pudica ditemukan Perpustakaan Utama, FISIP, dan Wisma Syahida. Kelengkapan data tentang tumbuhan polong di Kampus UIN Syarif Hidayatullah ini dapat digunakan oleh para mahasiswa untuk mempelajari keanekaragamnnya.
\end{abstract}

Kata kunci: Anak suku; Jelajah; Keanekaragaman; Puak; Tumbuhan polong

\section{Abstract}

Fabaceae is a plant with a pod-type fruit. A Habit of this family is not only trees but also herb. Fabaceae (legumes) is often found on the human environment around campus included in the State Islamic University (UIN) Syarif Hidayatullah, Jakarta. The Information about the legume herbs diversity on the UIN Syarif Hidayatullah yet available. The study was conducted using survey and literature methods. There were 3 species legume herbs in the campus, viz. Arachis pintoi Krapov. \& W. C. Greg., Mimosa diplotricha C. Wright ex Sauvalle, and M. pudica L. All species are differentiated into 2 subfamilies (Faboideae, Mimosoideae) and 2 tribes (Aeschynomeneae, Mimoseae). These species grow in the different locations. The Legumes only found at the Faculty of Medical and Health Science (FKIK) is A. pintoi. Mimosa diplotricha found growing around Central of Integrated Laboratory of the Faculty of Science and Technology, Main Library, FKIK, Faculty of Social and Political Sciences (FISIP), Wisma Syahida, Language Center, and Graduate School, while M. pudica found around Main Library, FISIP, and Syahida Inn. Data Completeness about legumes on Campus UIN Syarif Hidayatullah can be used by students to study plant diversity.

Keywords: Diversity; Legumes; Subfamilies; Survey; Tribes

Permalink/DOI: http//:dx.doi.org/10.15408/kauniyah.v10i1. 4872 


\section{PENDAHULUAN}

Area taman kampus yang terdapat di Kampus I dan II Universitas Islam Negeri (UIN) Syarif Hidayatullah Jakarta banyak ditumbuhi oleh tumbuhan dari suku Fabaceae yang berperawakan pohon (Irsyam \& Priyanti, 2016). Fabaceae merupakan kelompok tumbuhan berbunga yang memiliki buah bertipe buah polong (Simpson, 2010; APG IV, 2016; Irsyam \& Priyanti, 2016). Meskipun demikian, anggota suku tersebut juga dapat berperawakan terna. Secara ekologi, keberadaan tanaman terna di suatu lahan bermanfaat dalam perlindungan tanah, di antaranya perbaikan humus dan peredam laju air hujan ke tanah. Oleh sebab itu dapat mengurangi terjadinya erosi tanah (Barbour et al., 1987; Nahdi et al., 2012; Nahdi \& Darsikin, 2014).

Keanekaragaman tumbuhan polong berperawakan terna di taman-taman Kampus I dan II UIN Syarif Hidayatullah diuraikan pada makalah ini. Informasi tersebut untuk melengkapi publikasi sebelumnya (Irsyam \& Priyanti, 2016), sehingga dapat dijadikan sebagai rujukan oleh mahasiswa dalam mempelajari keanekaragamannya.

\section{MATERIAL DAN METODE}

Tetumbuhan di Kampus I dan II UIN Syarif Hidayatullah diamati pada bulan Oktober 2016. Metode jelajah yang digunakan pada penelitian ini mengacu pada Rugayah et al. (2004). Spesimen yang diamati terdiri atas ranting yang berbunga atau berbuah. Warna bunga, buah, dan biji dicatat langsung di lokasi tumbuhnya jenis karena mudah terjadi perubahan. Pengamatan spesimen dilakukan di Laboratorium Biologi Dasar Pusat Laboratorium Terpadu (PLT) UIN Syarif Hidayatullah Jakarta. Identifikasi spesimen mengacu pada Flora of Java vol. 1 (Backer \& Bakhuizen, 1963), Flora Malesiana vol. 11 part 1: Mimosaceae (Leguminosae-Mimosoideae) (Nielsen, 1992), dan Flora of China vol. 10: Fabaceae (Langran et al., 2010). Kunci determinasi tingkat anak suku dan jenis disusun mengikuti Vogel (1987) dan Irsyam \& Priyanti (2016). Istilah-istilah dalam pertelaan tumbuhan mengacu pada Rifai (2002) dan Beentje (2010).

\section{HASIL}

Tumbuhan polong yang menutupi lantai taman-taman Kampus I dan II UIN Syarif Hidayatullah Jakarta yaitu berperawakan terna sebanyak 3 jenis (Gambar 1). Arachis pintoi memiliki bunga tunggal berwarna kuning muncul di ketiak daun (aksilar). Mimosa diplotricha dan $M$. pudica memiliki perbungaan yang masing-masingnya terletak aksilar maupun terminal.
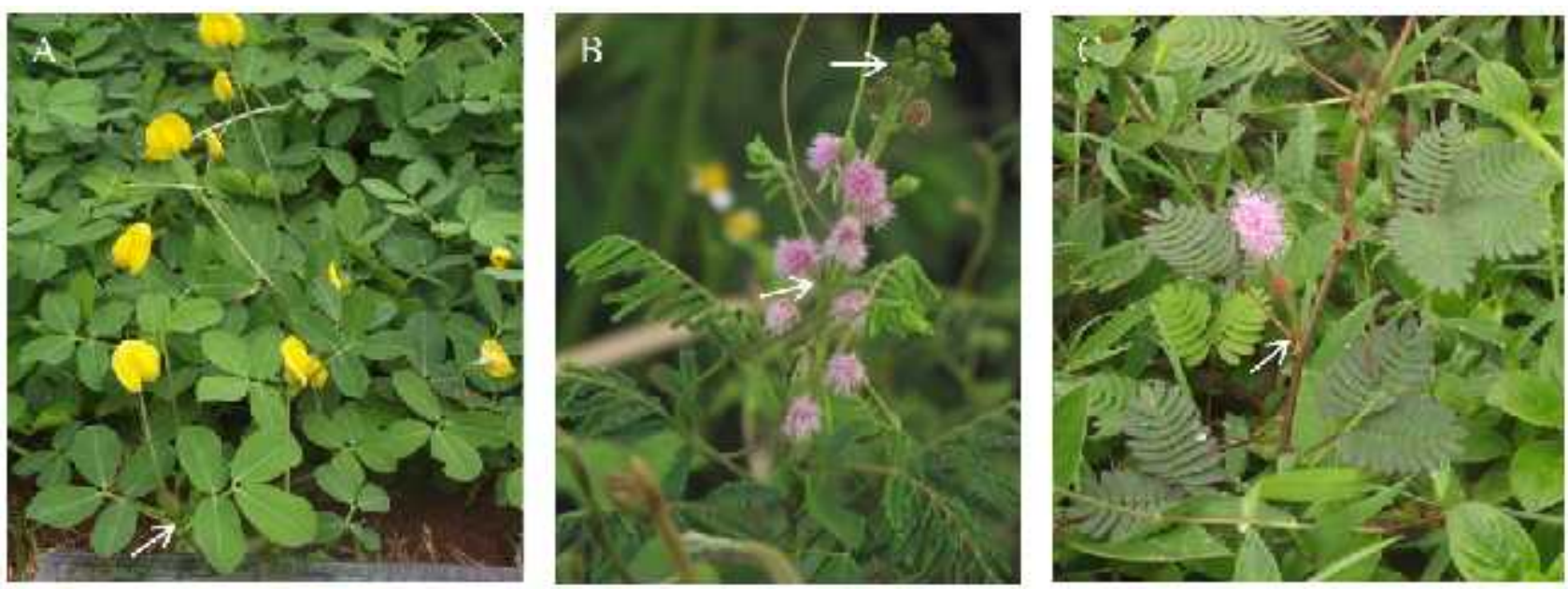

Gambar 1. Perawakan dan letak bunga tumbuhan polong di kampus UIN Syarif Hidayatullah Jakarta. A. Arachis pintoi berbunga tunggal dan terletak aksilar; B. Mimosa diplotricha dengan perbungaan aksilar dan terminal; C. Mimosa pudica dengan perbungaan aksilar; (panah menunjukkan letak bunga)

Jenis-jenis tumbuhan polong yang terdapat dalam Gambar 1 tergolong ke dalam 2 anak suku (Faboideae, Mimosoideae) dan 2 puak (Aeschynomeneae, Mimoseae) (Tabel 1). Kunci determinasi dan deskripsi masing- 
masing anak suku beserta jenisnya diuraikan di

bawah ini.

Tabel 1. Tumbuhan polong berperawakan terna di taman Kampus UIN Syarif Hidayatullah

\begin{tabular}{lll}
\hline \multicolumn{1}{c}{ Anak Suku } & \multicolumn{1}{c}{ Puak } & \multicolumn{1}{c}{ Jenis } \\
\hline Faboideae & Aeschynomeneae & Arachis pintoi Krapov. \& W.C.Greg. \\
Mimosoideae & Mimoseae & Mimosa diplotricha C. Wright ex Sauvalle \\
& & M. pudica L. \\
\hline
\end{tabular}

Kunci determinasi tingkat anak suku (dimodifikasi dari Irsyam \& Priyanti, 2016)

a. Bunga bersimetri bilateral, daun mahkota berlepasan, biji tidak memiliki pleurogram ... Faboideae

b. Bunga bersimetri radial, daun mahkota berlekatan, biji memiliki pleurogram Mimosoideae

\section{Anak Suku Faboideae (Papilionoideae)}

Secara umum, anak suku Faboideae memiliki bunga bersimetri bilateral yang bentuknya seperti kupu-kupu. Daun mahkotanya terdiri dari satu helai bendera, sepasang sayap, dan sepasang tunas yang saling melekat. Benang sarinya saling berlekatan dalam satu berkas (monodelphous) atau memberkas dua (diadelphous) (Langran et al., 2010).

Anggota Faboideae berperawakan terna di Kampus UIN Syarif Hidayatullah hanya diwakili oleh Arachis pintoi Krapov. \& W. C. Greg. yang dikelompokkan ke dalam puak Aeschynomeneae (Tabel 1). Puak tersebut dicirikan dengan adanya sekat transversal pada bagian polong dan pada saat masak setiap segmen polong akan berlepasan satu sama lain (Langran et al., 2010).

\section{Arachis pintoi Krapov. \& W.C. Greg.}

Arachis pintoi Krapov. \& W.C. Greg., Bonplandia (Corrientes) 8: 81-83, f. 2. 1994 ('Pintoi'). Tipe: Bahia, Gregory \& Krapovickas 12787; 31 March 1967; Brazil. Bahia. IPEAL, Cruz das Almas (MO iso).

Terna, merayap atau menanjak, panjang hingga lebih dari $20 \mathrm{~cm}$, bergeragih. Daun penumpu berlekatan dengan pangkal tangkai daun. Daun majemuk menyirip genap; anak daun 4 helai, melonjong hingga membundar telur sungsang, panjang 2,2-3,5 cm, lebar 1,1-
2,1 cm. Bunga tunggal, aksilar; gantilan membenang, putih. Daun kelopak menyelaput, bercuping 5; daun mahkota 5, berlepasan, terdiri atas bendera, sepasang lunas, dan sepasang sayap, merah; benang sari bertukal satu; putik 1. Buah tidak diamati

Distribusi: A. pintoi merupakan tumbuhan terna yang berasal dari Bahia, Brazil. Jenis ini telah banyak diintroduksi ke daerah tropis dan subtropis lainnya di dunia, seperti Argentina, Australia, Colombia, Amerika Tengah, Asia Tenggara, dan Pasifik (Cook, 1992).

Lokasi: Fakultas Kedokteran dan Ilmu

Kesehatan (FKIK).

Nama lokal: kacang hias, kacang pintoi (Indonesia).

Pemanfaatan: A. pintoi banyak dibudidayakan sebagai tanaman hias, pakan ternak, penyubur, dan penutup tanah (Cook, 1992; Ferguson \& Loch, 1999).

\section{Anak Suku Mimosoideae}

Anak suku Mimosoideae dicirikan dengan perbungaan bonggol atau bulir dengan daun mahkota yang saling berlekatan dan bersimetri radial. Selain itu di permukaan biji biasanya terdapat pleurogram yang berbentuk huruf U (Clark, 2014). Tumbuhan polong berperawakan terna dari anak suku Mimosoideae yang ditemukan di sekitar kampus antara lain $M$. diplotricha $\mathrm{C}$. Wright ex Sauvalle dan M. pudica L.

Secara taksonomi, keduanya dikelompokkan dalam puak Mimoseae. Puak tersebut memiliki benang sari yang berjumlah 10 helai atau kurang pada setiap bunganya (Langran et al., 2010). Marga Mimosa terdiri 500 jenis yang sebagian besar terdistribusi di kawasan Amerika Tropis. Marga ini mencakup jenis yang berduri, berdaun mudah mengatup karena sensitif oleh sentuhan, dan segmen buahnya 
akan berlepasan saat masak (Langran et al., 2010).

Kunci determinasi jenis

a. Batang menyilindris, daun majemuk campuran, pinnae $1-2$ pasang Mimosa pudica

b. Batang bersudut empat, daun majemuk menyirip ganda, pinnae 3-10 pasang Mimosa diplotricha

\section{Mimosa diplotricha C. Wright ex Sauvalle}

Mimosa diplotricha C. Wright ex Sauvalle, Anales Acad. Ci. Med. Habana 5: 405-406. 1869; Nielsen, Fl. Males. Ser. 1, Spermat. v. 11 (1): 184. 1992. Tipe: Wright 3541 (GH lecto; G, K, NY, US iso). Ditunjuk oleh Bassler, Feddes Repert 96: 602. 1985.

Mimosa invisa C. Mart., Flora 20(2), Beibl: 8: 121. 1837; Backer \& Bakh.f., Fl. Java 1: 561. 1963. Tipe: Luschnath in Martius, Hb. ft. bras. 172 (BR).

Terna, menanjak, panjang 2-6 $\mathrm{m}$. Batang bersudut empat, berduri di sepanjang sudut. Daun majemuk menyirip ganda; pinnae 5-9 pasang; pinnula $12-30$ pasang per pinna, melonjong, 3,5-5 $\times 1-2 \mathrm{~mm}$. Perbungaan bonggol, aksilar atau terminal; daun kelopak tidak ada; daun mahkota berlekatan, 4 helai, jambon; benang sari 8 helai, berlepasan; putik 1. Polong memita, agak melengkung, berbiji 4. Biji pipih, membundar telur sungsang, cokelat kekuningan.

Distribusi: Mimosa diplotricha berasal dari Brazil dan diintroduksi ke pelbagai kawasan tropis lainnya (Soerjani et al., 1987; Nielsen, 1992).

Lokasi: Pusat Laboratorium Terpadu (PLT) Fakultas Sains dan Teknologi (FST), Perpustakaan Utama, FKIK, Fakultas Sosial dan Ilmu Politik (FISIP), Wisma Syahida, Pusat Bahasa, dan Sekolah Pascasarjana.

Nama lokal: puteri malu; borang (Sunda); rembete (Jawa).

Pemanfaatan: Jenis ini juga ditanam sebagai penutup tanah dan pakan ternak (Backer \& Bakhuizen van den Brink, 1963; Nielsen, 1992).

\section{Mimosa pudica $\mathbf{L}$.}

Mimosa pudica L., Sp. Pl. 1: 518. 1753; Willd., Sp. PI. ed. 4 (4): 1032. 1806; Backer \& Bakh.f., Fl. Java 1: 561. 1963; Nielsen, Fl.
Males. Ser. 1, Spermat. v. 11 (1): 184. 1992. Tipe: Brazil, Clifford Herb. 208.3 (BM lecto). Ditunjuk oleh Brenan, Kew Bull. 10 (2): 185. 1955.

Terna, merayap atau tegak, panjang hingga $1,5 \mathrm{~m}$. Batang silindris, berduri, hijau atau keunguan. Daun majemuk campuran; pinnae $1-2$ pasang; pinnula $12-25$ pasang per pinna, melonjong hingga agak melancor, $6-15$ $\times 1,2-3 \mathrm{~mm}$. Perbungaan bonggol, aksilar; daun kelopak sangat kecil, $0,1 \mathrm{~mm}$; daun mahkota berlekatan, 4 helai, jambon; benang sari 4 helai, berlepasan, jambon; putik 1 . Polong memita, lurus, berbiji 4. Biji pipih, membundar telur sungsang, cokelat terang.

Distribusi: $M$. pudica berasal dari Amerika Selatan dan saat ini telah tersebar di seluruh kawasan tropis lainnya (Soerjani et al., 1987; Nielsen, 1992).

Lokasi: Perpustakaan Utama, FISIP, dan Wisma Syahida.

Nama lokal: puteri malu, si kejut; pis kucing (Jawa).

Pemanfaatan: Puteri malu ditanam sebagai tanaman penutup tanah di perkebunan kelapa dan pakan sapi (Soerjani et al., 1987). Selain itu, bagian akarnya juga dimanfaatkan sebagai obat diabetes oleh masyarakat di Bangladesh, India, Thailand, dan Filipina (Tunna et al., 2014).

\section{PEMBAHASAN}

Sistem klasifikasi yang digunakan pada penelitian ini mengacu pada Takhtajan (2009) dan Langran et al. (2010) yang sejalan dengan sistem APG IV (2016) yang penyusunannya berdasarkan pada analisis filogenetika (Irsyam \& Priyanti, 2016). Pada sistem klasifikasi tersebut, tumbuhan polong dikelompokkan ke dalam Suku Fabaceae yang mewadahi tiga anak suku, yaitu Caesalpinioideae, Faboideae, dan Mimosoideae.

Ketiga jenis tumbuhan polong berperawakan terna yang ditemukan di Kampus UIN Syarif Hidayatullah bukan merupakan tumbuhan asli Indonesia. A. pintoi sengaja ditanam di taman kampus karena memiliki bentuk mahkota dan warna yang indah sekaligus sebagai penutup lantai tanah kampus. Jenis tersebut berasal dari Bahia, Brazil, yang pada tahun 1992 sudah digunakan sebagai pakan ternak di Pulau Jawa dan belum 
terekam dalam publikasi-publikasi sebelumnya (Backer \& Bakhuizen van den Brink, 1963; Cook, 1992).

Kedua jenis Mimosa yang ditemukan di lingkungan kampus merupakan tumbuhan asli Amerika Tropis yang sudah ternaturalisasi di Indonesia sejak lama. Kehadiran $M$. diplotricha pertama kali direkam pada tahun 1900 di Jawa Tengah, sedangkan rekaman pertama M. pudica berasal dari Deli, Sumatera (Tjitrosoedirdjo et al., 2016). Keduanya dapat tumbuh di Kampus UIN Syarif Hidayatullah karena adanya persebaran biji dari lokasi sekitar kampus dan dianggap sebagai gulma. Hal tersebut sesuai dengan penelitian terdahulu bahwa $M$. diplotricha dan $M$. pudica dapat tersebar luas melalui pemencaran biji oleh aliran air hujan, penempelan biji pada rambutrambut dan kulit hewan, pakaian, kendaraan, serta alat-alat pertanian (Soerjani et al., 1987; Sankaran, 2015).

Tumbuhan polong berperawakan terna yang tumbuh di taman-taman Kampus I dan II UIN Syarif Hidayatullah Jakarta lebih sedikit (3 jenis) dibandingkan dengan tumbuhan polong berperawakan pohon (Irsyam \& Priyanti, 2016). Jika dibandingkan dengan penelitian Akbarini (1998) yang mendapatkan 14 jenis tumbuhan polong berperawakan terna di Kampus Universitas Padjadjaran, jenis-jenis tumbuhan polong yang tumbuh ditaman kampus UIN Syarif Hidayatullah lebih sedikit. Hal tersebut disebabkan pembersihan lantai taman yang dilakukan secara berkala dan adanya anggapan bahwa tumbuhan terna yang hidup di lantai taman-taman kampus merupakan gulma yang dapat berkompetisi dengan tanaman hias di sekelilingnya sehingga dapat berpengaruh terhadap pertumbuhan dan perkembangan tanaman utama. Mimosa pudica yang dianggap sebagai gulma ditemukan juga pada tegakan tanaman muda Eucalyptus spp. (Faisal et al., 2013) serta kebun atau pekarangan (Soerjani et al., 1987). Meskipun demikian, tumbuhnya $M$. diplotricha var. diplotricha dan $M$. pudica dapat mengikat unsur nitrogen udara sehingga dapat menyuburkan tanah serta berperan dalam penghasil oksigen bagi lingkungan di sekitarnya (Soerjani et al., 1987).

Nama M. invisa Mart. yang digunakan oleh Backer \& Bakhuizen van den Brink
(1963) dalam Flora of Java vol. 1 mirip dengan spesimen tipe (Wright 3541) yang ditunjuk oleh Bassler (1985) yang diidentifikasi sebagai $M$. diplotricha $\mathrm{C}$. Wright ex Sauvalle. Nama $M$. invisa C. Martius ex Colla merupakan nama yang sah untuk $M$. rhodostachya (Benth.) Benth. dan bukan sinonim untuk M. diplotricha (Barneby, 1997).

$M$. diplotricha terdiri atas dua varietas, yaitu var. diplotricha dan var. inermis. Perbedaan di antara kedua varietas tersebut terletak pada keberadaan duri. Varietas yang ditemukan di lingkungan Kampus I dan II UIN Syarif Hidyatullah yaitu $M$. diplotricha var. diplotricha yang batangnya ditutupi duri pada setiap sudutnya. $M$. diplotricha var. inermis (Adelb.) Veldk. merupakan varietas tidak berduri yang berasal dari Pulau Jawa (Nielsen, 1992), namun tidak tumbuh di sekitar kampus.

\section{KESIMPULAN}

Sebanyak 3 jenis tumbuhan polong berperawakan terna tumbuh di Kampus I dan II UIN Syarif Hidayatullah Jakarta. Jenis-jenis tersebut dikelompokkan ke dalam anak suku Faboideae dan Mimosoideae serta puak Aeschynomeneae dan Mimoseae. Data yang diperoleh dapat melengkapi publikasi sebelumnya sebagai sarana pembelajaran keanekaragaman tumbuhan di kampus.

\section{REFERENSI}

Akbarini, D. (1998). Flora kampus Universitas Padjadjaran Jatinangor: Dikotil (Magnoliaceae-Buxaceae). (Skripsi). Universitas Padjadjaran.

Angiosperm Phylogeny Group [APG] IV. (2016). An update of the Angiosperm Phylogeny Group classification for the orders and sukues of flowering plants: APG IV. Botanical Journal of the Linnean Society, 181: 1-20. doi:10.1111/boj. 12385

Backer, C. A. \& Bahkuizen van den Brink, R.C. Jr. (1963). Flora of Java. (vol. 1). (pp. 615, 628). Groningen: P. Noordhoff.

Barbour, M. G., Burk, J. H. \& Pitts, W. D. (1987). Terrestrial plant ecology $2^{\text {nd }}$ edition California. Inc. Menlo Park: Benjamin/Cumming Publising Company. 
Barneby, R. C. (1987). A Note on Mimosa invisa C. Martius ex colla and $M$. invisa C. Martius (Mimosaceae). Brittonia 39(1): 49-50. doi: 10.2307/2806973

Beentje, H. (2012). The kew plant glossary: An illustrated of plant terms. (pp.5-132). Kew: Royal Botanic Garden.

Clark, R. (2014). Leguminosae (Fabaceae): Papilionoideae. In Utteridge, T. \& Bramley, G. (Eds.). The Kew: Tropical plant families identification handbook. (pp. 60-61). Kew: Royal Botanic Garden.

Cook, B. G. (1992). Arachis pintoi Krap. \& Greg., nom. nud. In Mannetje, L.'t \& Jones, R.M. (Eds.). Plant Resources of South-East Asia No. 4: Forages. (pp. 4850). Wageningen: Pudoc.

Faisal R., Siregar, E. B. M., \& Ana, N. (2013). Inventarisasi gulma pada tegakan tanaman muda eucalyptus spp. http://202.0.107.5/index.php/PFSJ/article /viewFile/3525/1683

Ferguson, J. E. \& Loch, D. S. (1999). Arachis pintoi in Australia and Latin America. In Loch, D. S., \& Ferguson, J. E (Eds). Forage seed Production. Tropical and Subtropical Species (vol. 2). (pp 427434). UK: CABI Publishing.

Irsyam, A. S. D. \& Priyanti. 2016. Suku Fabaceae di Kampus Universitas Islam Negeri (UIN) Syarif Hidayatullah, Jakarta, Bagian 1: Tumbuhan polong berperawakan pohon. Al Kauniyah Jurnal Biologi, 9(1), 37-43. doi: 10.15408

Langran, X., Dezhao, C., Xiangyun, Z., Puhua, H., Zhi, W., Ren, S.,...Sokoloff, D. D. (2010). Flora of China: Fabaceae. (vol. 10). Beijing: Science Press.

Nahdi, M. S., \& Darsikin. (2013). Distribusi dan kemelimpahan spesies tumbuhan bawah pada naungan Pinus merkusii, Acacia auriculiformis, dan Eucalyptus alba di Hutan Gama Giri Mandiri Yogyakarta. Jurnal Natur Indonesia, 16(1), 33-41.
Nahdi, M. S., Marsono, D., Sugandawati, T. M. \& Baiquni. (2012). Konservasi ekosistem lahan kritis untuk pemenuhan hak hidup masyarakat (Studi kasus di Imogiri Yogyakarta). Millah, 12(1): 124142.

Nielsen, I. C. (1992). Flora Malesiana ser. 1. (vol. 11(1): Mimosaceae (LeguminosaeMimosoideae)). (pp 1-226). Leiden: National Herbarium of the Netherlands.

Rifai, M. A. (2002). Kamus Biologi. Jakarta: Balai Pustaka.

Rugayah, Retnowati, A., Windadri, F. I., \& Hidayat, A. (2004). Pengumpulan data taksonomi. In Rugayah, Widjaja, E. A., \& Praptiwi (Eds). Pedoman pengumpulan data keanekaragaman flora. Bogor: Puslit-LIPI.

Simpson, M. G. (2010). Plant systematics. California: Elsevier Academic Press.

Sinkaran, K. V. (2015). Mimosa diplothrica: Giant sensitive plant. India: Kerala Forest Research Institute.

Soerjani, M., Kostermans, A. J. G. H., \& Tjitrosoepomo, G. (1987). Weeds of rice in Indonesia. Jakarta: Balai Pustaka.

Tjitrosoedirdjo, S. S., Mawardi, I. \& Tjitrosoedirdjo, S. (2016). 75 Important invasive plant species in Indonesia. (pp. 44-46). Bogor: SEAMEO BIOTROP.

Tunna, S. T., Ahmed, Q. U., Uddin, A. B. M. H. \& Sarker, Md. Z. I. (2014). Weeds as alternative useful medicinal source: Mimosa pudica Linn. on diabetes mellitus and its complications. Advanced Material Research, 995: 49-59. doi: 10.4028.

Vogel, E. F. (1987). Guidelines for the preparation of revisions. In Vogel, E. F (Ed.). Manual of herbarium taxonomy theory and practice. (p. 76). Jakarta: UNESCO. 